proposals may divert attention from the need for rapid and radical steps to deal with the gorwing problems of staffing in N.H.S. hospitals.

At present two thirds of all senior house officers, half of all registrars, and one quarter of all senior registrars in these hospitals were born overseas. In some specialties-such as neurosurgery, cardiothoracic surgery, and orthopaedics-over two thirds of the registrars are foreign-born doctors. ${ }^{4}$ These figures have two implications: they show that any change in world events that led to a sudden reduction in medical immigration to the United Kingdom could be disastrous for the N.H.S., and they also demonstrate that at present career prospects in a number of specialties are such that hardly any British graduates can be attracted into training posts. At the same time patients are often badly served: casualty services in many parts of the country are quite inadequate, waiting lists are long, and outpatient appointments are delayed for months. News of this gloomy prospect has penetrated into teaching hospitals, and it is perhaps symptomatic of the difficulties of the hospital service that more students than ever before are showing interest in a career in general practice.

Redistribution of registrar posts will do virtually nothing to remedy the serious difficulties in the hospital service, and indeed tinkering with the problem seems more likely just to cause discontent in the teaching hospitals.

There are two separate problems that must be acknowledged by hospital staff-for at present they are not given the attention they deserve. Firstly, registrars are reluctant to take jobs outside teaching hospitals because they know that once they step outside the magic circle they are unlikely to return. There are far too few rotating appointments which require a registrar to spend one year in a regional hospital. Until this situation is changed an ambitious young doctor will prefer to take any job in a teaching hospital-even if it means a year doing laboratory research in which he has little interest-rather than risk sinking without trace in a regional hospital.

Secondly, the freeze on registrar posts must mean that more and more of the routine work in district hospitals will need to be done by part-time medical assistants-married women doctors and general practitioners. The combination of this trend with the steady reduction in the hours worked by junior staff has been responsible for the growing difficulty of arranging cover for emergencies at night and at weekends. It seems inevitable that more emergency work will be done by consultants; but once this change has been accepted it should be possible to devise an equitable system for organizing emergency cover and paying consultants accordingly.

The last decade has seen the Department of Health warily picking its way between pressure groups from the teaching hospitals, hospital junior staff, and regional consultants, and the result has been an unsatisfactory compromise that has been saved from total collapse only by the fortuitous existence of a ready supply of young doctors from overseas. Though it is not an exact parallel, the N.H.S. should profit from the experience of London Transport: reliance on Commonwealth immigrants to solve staffing problems can only be a temporary solution and the supply may dry up very suddenly. Hospital jobs throughout the country must be able to attract graduates fron: our own medical schools if the N.H.S. is to survive, and this is unlikely to be achieved by switching a few registrars from London into the provinces.

1 D.H.S.S. circular to secretaries of all boards of governors. Redistribution of Registrar and Senior Registrar Medical Posts. 23 May 1973. Cited by Bowden, P., and Clare, A. W., Lancet, 2, 857.

2 D.H.S.S. circular to secretaries of all boards of governors. Redistribution of Registrar and Senior Registrar Posts. 8 August 1973.
3 British Medical fournal Supplement, 1973, 4, 37

+ On the State of the Public Health. The Annual Report of the Chief Medical Officer of the Department of Health and Sociai Security for the year 1972. London, H.M.S.O., 1973.

\section{Forms of Colitis}

The first descriptions of ulcerative colitis are lost in early historical writings on chronic non-contagious diarrhoea, but it was probably first referred to as a specifically named disease by Sir Samuel Wilks in 1859 when describing the unfortunate Miss Banks and the morbid appearance of her intestine. ${ }^{1}$ In contrast Crohn's disease has had a more precise historical passage, landmarks being Crohn's own paper in $1932^{2}$ and that by H. E. Lockhart-Mummery and B. C. Morson in $1960^{3}$ on its colonic lesions.

In their classical forms ulcerative colitis and Crohn's disease are easily distinguished on clinical, radiological, and pathological criteria. ${ }^{4}$ The distinction has no aetiological basis, and therefore the diagnosis, though clear-cut at either end of the spectrum, leads to difficulties in the middle ground, even to the extent that they have been considered variants of a single disease. The confusion is partly because no one feature, clinical or pathological, is either invariably present or invariably absent. Non-caseating giant cell granulomata, which most people accept as confirming the diagnosis of Crohn's disease, occur in only about $50 \%$ of otherwise typical cases, ${ }^{5}$ and even these have been described in ulcerative colitis. ${ }^{6}$ Thus at present, while there is no diagnostic test to distinguish Crohn's disease from ulcerative colitis, the separation has to be based on a wide variety of criteria. In this respect a painstaking study of $M . G$. Cook and M. F. Dixon ${ }^{7}$ is of considerable interest. They chose 95 pathological features, recorded the observer variation in recognizing these features, and tabulated them in terms of their diagnostic value in distinguishing Crohn's disease from ulcerative colitis. They studied material from 50 cases of Crohn's disease and 50 cases of ulcerative colitis, all with a confident clinical diagnosis. They concluded that along with certain other features linear ulceration and deep fissures seen macroscopically, together with an aggregated inflammatory pattern and sarcoid-like granulomata, are the best indicators of Crohn's disease. These were not seen in ulcerative colitis, and there was high observer agreement on them. A healed granular mucosa, the absence of fissures, irregular glands, and continuous inflammation have high diagnostic value for ulcerative colitis, being features of all their cases. But crypt abscesses, lymphangiectasia, and submucosal oedema were not of great value as is sometimes held. While 18 of the 19 cases of Crohn's disease showed transmural inflammation, so did 4 of the 23 cases of ulcerative colitis. It is salutary to realize that ${ }^{8}$ Hadfield, writing on Crohn's disease in 1939, emphasizes almost the same features. This highlights the feeling that routine histological examination of operative material may have reached its limit and more discriminating tests are required, perhaps from other pathological disciplines.

Histochemical techniques show mainly non-specific changes in both diseases, a reflection of epithelial cell regeneration. But observations of epithelial mucins have been rewarding. They are more reduced in ulcerative colitis than in Crohn's disease. ${ }^{9}$ This has also been shown to have a surprisingly high discriminative value in routine histology, expressed as goblet cell depletion. ${ }^{10}$ Electron microscopy has not yet provided findings of major diagnostic importance. Some differences are present, but their significance has still to be determined. 
Damage to epithelial cells is earlier in ulcerative colitis than in Crohn's disease, and there is degeneration of reticulin in the mucosa. ${ }^{11}$ On the other hand in Crohn's disease there is no initial epithelial abnormality while some lymphocytes in the lamina propria show changes suggestive of transformation into plasma cells. In addition intramural bacteria have been seen in some cases of Crohn's disease. ${ }^{12}$ If this observation is substantiated it might link up with the transmissible agent described by D. N. Mitchell and R. J. Rees. ${ }^{13}$

Immunology is throwing light on the possible pathogenesis of these two diseases but has little to offer, at present, of discriminative value. Colonic and antibacterial antibodies are found in both diseases, and, while technical difficulties may account for many of the discrepancies reported, no clear individual disease pattern has been established. ${ }^{14}$ The immunofluorescent patterns in colonic biopsies show abnormal numbers of cells containing $1 \mathrm{gA}$ and $1 \mathrm{gG}$, but the specificity of these abnormalities is not known. ${ }^{15}$ Lymphocyte cytotoxicity to colonic epithelium has also been reported in both Crohn's disease and ulcerative colitis. ${ }^{16} \mathrm{~J}$. M. T. Willoughby and Mitchell found that suspensions of sarcoid spleen cells inhibit white cell migration in patients with Crohn's disease but not in those with ulcerative colitis, ${ }^{17}$ and G. Bendixen, ${ }^{18}$ using gut mucosal antigens, found a similar inhibition in patients with ulcerative colitis. However, only limited numbers of each group showed inhibition, thus diminishing the value of the test. All these investigations suggest that patients with ulcerative colitis or Crohn's disease do have altered immunological reactivity, but its role in the aetiology of the diseases remains conjecture, and so far the tests do not have much diagnostic value.

J. Hywel Jones and colleagues have tried a different approach. ${ }^{10}$ Using a method of discriminant analysis on up to 40 attributes in patients with colonic Crohn's disease or ulcerative colitis, they found the best separation between the two could be achieved using only five. These were digital examination of the rectum, the mucosal vascular pattern seen at sigmoidoscopy, the granularity of the diseased area visualized by $x$-ray, mucin depletion of goblet cells judged from a rectal biopsy, and the occurrence of tenesmus elicited in the history. However, until the aetiology of these diseases is discovered it appears unlikely that the ideal diagnostic test will be found. Work on the experimental production of Crohn's disease and ulcerative colitis is still well short of this goal. ${ }^{19} 20$

At present, therefore, a diagnosis is made on a variety of pathological and clinical criteria, and Cook and Dixon ${ }^{7}$ have indicated the most reliable pathological ones. Unfortunately atypical or unclassified cases are numerous-10\% according to T. H. Kent, ${ }^{21} 12$ of 109 cases in J. Hywel Jones and colleagues' series, ${ }^{10} 24$ out of 95 in D. J. Glotzer and colleagues' work, ${ }^{22}$ and even 8 of 50 in Cook and Dixon's paper. ${ }^{7}$ Further study of this group is clearly needed. To insist on labelling them either Crohn's disease or ulcerative colitis is too narrow an approach, for it presupposes that only these two forms of non-specific colitis exist. Experience suggests this is not so.

A. Marston and colleagues ${ }^{23}$ have described a separate group now clearly recognized as ischaemic colitis. W. T. Miller and colleagues $^{24}$ also described a possibly separate group with evanescent colitis. Hywel Jones and colleagues, using statistical analysis, suggest that, while ulcerative colitis is a homogeneous clinical entity, Crohn's disease is not. H. E. Lockhart-Mummery and others ${ }^{2526}$ have shown that Crohn's disease has a bimodal age distribution. Of Lockhart-Mummery's cases over 45 years of age $70 \%$ had the disease confined to the distal colon and enjoyed an excellent prognosis. Did they have yet another disease ? Furthermore, patients with limited proctitis could be one more group. Thus R. G. Farmer and C. H. Brown ${ }^{27}$ and J. E. Lennard-Jones and colleagues ${ }^{28}$ showed that only $10 \%$ of these cases go on to classical ulcerative colitis. While these observations by no means prove the existence of new diseases or syndromes they provoke such thoughts, particularly in relation to those patients who, at present, defy accurate classification.

With the advent of colonoscopic biopsies we are reminded of the effect biopsy is having on renal and hepatic nomenclature, "end-stage" kidney and cirrhosis being the final path of many newly recognized forms of nephritis and hepatitis. Perhaps the dynamic view allowed by colonoscopy and biopsy will show that the colectomy specimen or "end-stage" colon is the result of numerous types of colitis.

${ }^{1}$ Goligher, J. C., de Dombal, F. T., Watts, Z. McK., and Watkinson, G., in Ulcerative Colitis, Chap. 1. London, Baillière, Tindall and Cassell, 1968

2 Crohn, B. B., Ginzburg, L., and Oppenheimer, G. D., fournal of the American Medical Association, 1932, 99, 1323.

3 Lockhart-Mummery, H. E., and Morson, B. C., Gut, 1960, 1, 87.

4 Lennard-Jones, J. E., Lockhart-Mummery, H. E., and Morson, B. C., Gastroenterology, 1968, 54, 1162.

Gastroenterology, 1968, 54, 1162. . P., Gastrointestinal Pathology, p. 269.
Morson, B. C., and Dawson, I. M. P., Oxford, Blackwells, 1972 .

${ }^{6}$ Gonzales-Licea, A., and Yardley, J. H., Gastroenterology, 1966, 51, 825.

Cook, M. G., and Dixon, M. F., Gut, 1973, 14, 255.

Hadfield, G., Lancet, 1939, 2, 773.

9 Filipe, M. I., and Dawson, I., Gut, 1970, 11, 229.

10 Jones, J. H., et al., Quarterly fournal of Medicine, 1973, 42, 715

11 Donnellan, W. L., Gastroenterology, 1966, 50, 519.

12 Aluwhare, A. P. R., Clinics in Gastroenterology, 1972, 1, No. 2.

13 Mitchell, D. N., and Rees, R. J. W., Lancet, 1970, 2, 168.

14 Deodhar, S. D., Michener, W. M., and Farmer, R. G., American Fournal of Clinical Pathology, 1969, 51, 591 .

15 Soltoft, J., Binder, V., and Gudmand-Hoyer, E., Scandinavian fournal of

Gastroenterology, 1973, 8, 293.
Shorter, R. G., Huizenga, K. A., ReMine, S. G., and Spencer, R. J., Gastroenterology, 1970, 58, 843 .

17 Willoughby, J. M. T., and Mitchell, D. N., British Medical fournal, 1971, 3, 155.

18 Bendixen, G., Gut, 1969, 10, 631.

19 Kane, S. P., Clinica in Gastroenterology, 1972, 1, No. 2.

20 Walt, J., and Marcus, R., Gut, 1973, 14, 506.

21 Kent, T. H., Ammon, R. K., and DenBesten, L., Archives of Pathology, $1970,89,20$.

22 Glotzer, D. J., et al., New England fournal of Medicine, 1970, 282, 582.

${ }^{23}$ Marston, A., Pheils, M. T., Thomas, M. L., and Morson, B. C., Gut, 1966, 7, 1 .

${ }^{24}$ Miller, W. T., DePoto, D. W., Scholl, H. W., and Raffensperger, E. C., Radiology, 1971, 100,71.

25 Lockhart-Mummery, H. E., British fournal of Surgery, 1972, 59, 823.

26 Hoffman, W. A., and Rosenberg, M. A., American fournal of Gastroenterology, $1972,58,508$.

27 Farmer, R. G., and Brown, C. H., Diseases of the Colon and Rectum, 1972,, $15,142$.

${ }^{28}$ Lennard-jones, J. E., et al., Gut, 1962, 3, 201.

\section{Drivers in Court}

Many people regard the motoring offender as differentsomehow not quite a criminal. But most offenders of whatever sort regard the other man's crime as different, and tend to justify their own misbehaviour as not really harming anyone or as just bad luck. The stealer feels far removed from the murderer, while the murderer regards the stealer as a professional thief-“a thing I could never do." Perhaps, then, the fact that there are so many drivers is sufficient reason for this tolerance for the motoring offender. But a non-driving mother with small children who lives near a busy highway might have contrary opinions.

Yet it would be surprising if motoring offenders really were so very different, for breaking traffic regulations and driving badly are forms of deviant behaviour, and deviant behaviour whether it is getting drunk, generally misbehaving, or committing an aggressive or acquisitive crime, can 